\title{
Composição química, digestibilidade e disponibilidade de capim-elefante cv. Napier manejado sob pastejo rotativo ${ }^{1}$
}

\author{
Fermino Deresz ${ }^{2}$, Matheus Linhares Paim-Costa ${ }^{3}$, Antônio Carlos Cóser ${ }^{2}$, Carlos Eugênio \\ Martins $^{2}$, João Batista Rodrigues de Abreu ${ }^{4}$
}

\footnotetext{
1 Parte do trabalho de dissertação de Mestrado do segundo autor, desenvolvida pelo Programa de Pós-Graduação em Zootecnia da Universidade Federal Rural do Rio de Janeiro - UFRRJ

2 Embrapa Gado de Leite, Rua Eugênio do Nascimento, 610, CEP: 36038-330, Juiz de Fora, MG, Brasil

${ }^{3}$ Mestre em Zootecnia da UFRRJ, Antiga Rodovia Rio São Paulo, km 47, CEP: 23851-970, Seropédica, RJ, Brasil.

${ }^{4}$ UFRRJ, Antiga Rodovia Rio São Paulo, km 47, CEP: 23851-970, Seropédica, RJ, Brasil.
}

RESUMO - O trabalho foi realizado com o objetivo de avaliar a composição química, a digestibilidade in vitro da matéria seca (DIVMS), a disponibilidade de forragem de capim-elefante cv. Napier e a produção de leite (PL). As estimativas de disponibilidade de MS foram realizadas mensalmente, um dia antes da entrada dos animais nos piquetes, por meio da técnica do pastejo simulado. As amostras de forragem foram colhidas observando-se a altura do resíduo pós-pastejo do ciclo anterior Foram colhidas seis amostras por tratamento de touceiras classificadas como de alturas alta, média e baixa. As amostras foram pesadas, obtendo-se a média de forragem das três touceiras em cada tratamento em cada ciclo de pastejo. Subamostras foram retiradas para determinação da composição química (MS, PB, FDN e FDA) e da DIVMS. A pastagem foi manejada sob pastejo rotativo, com três dias de ocupação e 30 dias de intervalo de desfolha, com duas repetições de área, utilizando-se vacas Holandês x Zebu, conforme os seguintes tratamentos: pastagem, sem suplementação $\left(\mathrm{T}_{0}\right)$, suplementação com concentrado durante 60 dias $\left(\mathrm{T}_{60}\right)$ e/ou 120 dias de lactação $\left(\mathrm{T}_{120}\right)$. Foi fornecido nos tratamentos $\mathrm{T}_{60}$ e $\mathrm{T}_{120} 1 \mathrm{~kg}$ de concentrado $(20 \%$ de $\mathrm{PB}$ e $70 \%$ de NDT) para cada $2 \mathrm{~kg}$ de leite produzido acima de $10 \mathrm{~kg}$. A pastagem foi adubada com $1.000 \mathrm{~kg} / \mathrm{ha} / \mathrm{ano}$ da fórmula 20:05:20. Não houve diferença na composição química e na DIVMS entre os tratamentos, cujos valores médios foram de 13,6; 69,1; 39,5 e 63,8\% para PB, FDN, FDA e DIVMS, respectivamente. A disponibilidade de MS também não foi afetada pelos tratamentos, tanto por área $(\mathrm{kg} / \mathrm{ha}$ de MS) quanto por vaca $(\mathrm{kg} / \mathrm{dia})$, obtendo-se médias de $1.480 ; 1.760$ e 1.870 e 12,$4 ; 14,7$ e 15,6 kg/vaca/dia, para $T_{0}, T_{60}$ e $T_{120}$, respectivamente. A PL não diferiu entre os tratamentos, com média de $11,65 \mathrm{~kg} / \mathrm{vaca} / \mathrm{dia}$, porém com diferenças entre as médias nos estádios de lactação: 15,1; 11,6 e 8,2 kg/vaca/dia de 1 a 60 dias, de 60 a 120 dias e acima de 120 dias. Nas condições deste experimento, os tratamentos não afetaram as variáveis estudadas.

Palavras-chave: forragem disponível, gramíneas tropicais, qualidade de forragem, vacas em lactação

\section{Chemical composition, in vitro dry matter digestibility and forage mass of elephantgrass cv. Napier pasture managed in a rotational grazing system}

ABSTRACT - One experiment was run to study the chemical composition, in vitro dry matter digestibility and the dry matter mass of elephantgrass pasture cv. Napier. Estimates of forage mass were accomplished monthly according to the hand plucking technique with samples being taken one day before the cows were turned into the paddocks. Forage samples were taken observing the stubble height of the pasture in the former grazing cycle. Six samples per treatment were collected from high, medium and low representative tuffs in the sampled paddocks. Samples were weighted in order to obtain the average forage yield per treatment on each grazing cycle. Forage subsamples were analyzed for chemical composition (DM, CP, NDF e ADF) and in vitro dry matter digestibility (IVDMD). Pasture was managed in a rotational grazing system of 33 days grazing cycle with three days grazing period and 30 days rest period. There were two replication units per treatment. Twenty four crossbred Holstein $\mathrm{x}$ Zebu cows were used, there being eight per treatment. The following treatments were studied: Elephantgrass pasture with no concentrate $\left(\mathrm{T}_{0}\right)$; Elephantgrass supplemented with concentrate during the first 60 days of lactation $\left(\mathrm{T}_{60}\right)$ and a 120 days of lactation $\left(\mathrm{T}_{120}\right)$. Cows on treatments $\mathrm{T}_{60}$ and $\mathrm{T}_{120}$ received $1 \mathrm{~kg}$ of concentrate $(20 \% \mathrm{CP}$ and $70 \% \mathrm{TDN})$ for each $2 \mathrm{~kg}$ of milk above $10 \mathrm{~kg}$, daily. Pasture was fertilized with 1,000 kg/ha/year of a 20:05:20 formula. There was no treatment effect on the forage chemical composition and IVDMD figures. Mean values for CP, NDF, ADF and IVDMD were: 13.6, 69.1, 39.5, and 63.8\% for CP, NDF, ADF and IVDMD, respectively. There was no treatment effect on forage mass $(1,480 ; 1,760$ and $1,870 \mathrm{~kg} \mathrm{DM} / \mathrm{ha})$ and daily forage allowance per cow $(12.4 ; 14.7$ and $15.6 \mathrm{~kg} \mathrm{DM} /$ day). There was no treatment effect for milk yield averaging $11.65 \mathrm{~kg} / \mathrm{cow} /$ day. However there was treatment effect for stage of lactation, which averaged 15.1, 11.6, and $8.2 \mathrm{~kg} / \mathrm{cow} / \mathrm{day}$ for 1 to 60,60 to 120 and over 120 days, respectively.

Key Words: available forage, tropical grasses, forage quality, lactating cows 


\section{Introdução}

Nas principais regiões produtoras de leite do Brasil, nota-se aumento na implantação de sistemas intensivos de produção de leite em pastagens, buscando maior eficiência no uso de insumos e recursos forrageiros (Aroeira et al., 2004; Deresz, 2001). Conseqüentemente, são necessárias maiores informações sobre espécies forrageiras de alta produtividade e qualidade para alimentação destes rebanhos.

O manejo adequado de forrageiras está intimamente ligado às avaliações freqüentes na pastagem e aos ajustes na taxa de lotação, de modo que se evite o sub ou superpastejo. Estas avaliações podem ser feitas de diferentes formas, mas o método utilizado deve representar a realidade das pastagens, sem, contudo, se tornar excessivamente trabalhoso e dispendioso.

O elevado potencial de produção do capim-elefante evidencia a importância desta espécie para a produção animal. No entanto, sua alta produtividade na estação chuvosa e a redução do crescimento na época seca podem resultar em grandes variações nas características morfológicas e nos teores de MS na planta, impondo sérias dificuldades à utilização dos métodos de amostragem, que devem ser sensíveis em ambas as situações - crescimento rápido e lento das plantas (O’ Rourke, 1984). Além disso, o hábito de crescimento do capim-elefante e sua desuniformidade na cobertura do solo também limitam a acurácia dos avaliadores, por não possibilitar bom domínio da cobertura e distribuição espacial da pastagem como um todo.

A determinação da quantidade de forragem disponível é importante, pois possibilita estimar o desempenho animal, o consumo e suas perdas. Portanto, o peso da forragem consiste em importante medida de crescimento, por permitir calcular a taxa de lotação e interpretar o rendimento da produtividade animal (Estrada et al., 1991). Todavia, a estimativa da forragem disponível em experimentos em pastejo é freqüentemente associada a alto erro experimental, podendo variar significativamente entre os métodos usados para essa finalidade (Aiken \& Bransby, 1992).

Por outro lado, a técnica do pastejo simulado para estimativa da forragem potencialmente consumível em pastagens de capim-elefante (Aroeira et al.,1999) é recente e tem sido intensamente utilizada nos experimentos de pastejo envolvendo avaliações dessa forrageira.

Outro fator relevante que pode ser utilizado como variável de qualidade é a composição química. Contudo, deve-se considerar que essa composição é dependente da idade da planta e de aspectos genético e ambiental.

Os principais constituintes químicos das plantas forrageiras podem ser divididos em duas grandes categorias: os de menor digestibilidade no processo de digestão, constituído pela estrutura da parede celular, e os que possuem alta digestibilidade no conteúdo celular, que envolvem substâncias solúveis ou levemente solúveis em água, como amido, lipídios e algumas proteínas digeridas por enzimas de microrganismos (Costa et al., 2005).

Este trabalho foi conduzido com o objetivo de avaliar a disponibilidade de forragem de capim-elefante cv. Napier, a composição química, a digestibilidade in vitro da matéria seca e a produção de leite durante a época chuvosa.

\section{Material e Métodos}

O experimento foi conduzido no município de Valença, RJ, durante o período de outubro de 2000 a junho de 2001.

A região apresenta precipitação pluviométrica anual de $1.225 \mathrm{~mm}$ (média dos últimos dez anos), temperatura média anual de $23^{\circ} \mathrm{C}$, com média das máximas de $30^{\circ} \mathrm{C}$ e média das mínimas de $17^{\circ} \mathrm{C}$, e umidade relativa do ar de $72 \%$. O clima da região, segundo a classificação de Koppen é do tipo Cwa,

Tabela 1 - Precipitação pluviométrica $(\mathrm{mm})$, temperaturas médias mensais, médias das máximas e mínimas $\left({ }^{\circ} \mathrm{C}\right)$ e umidade relativa do ar (\%), durante o período experimental

Table 1 - Average rainfall $(\mathrm{mm})$, monthly temperatures (low, mean and high $-{ }^{\circ} \mathrm{C}$ ) and air humidity $(\%)$, during the experimental period

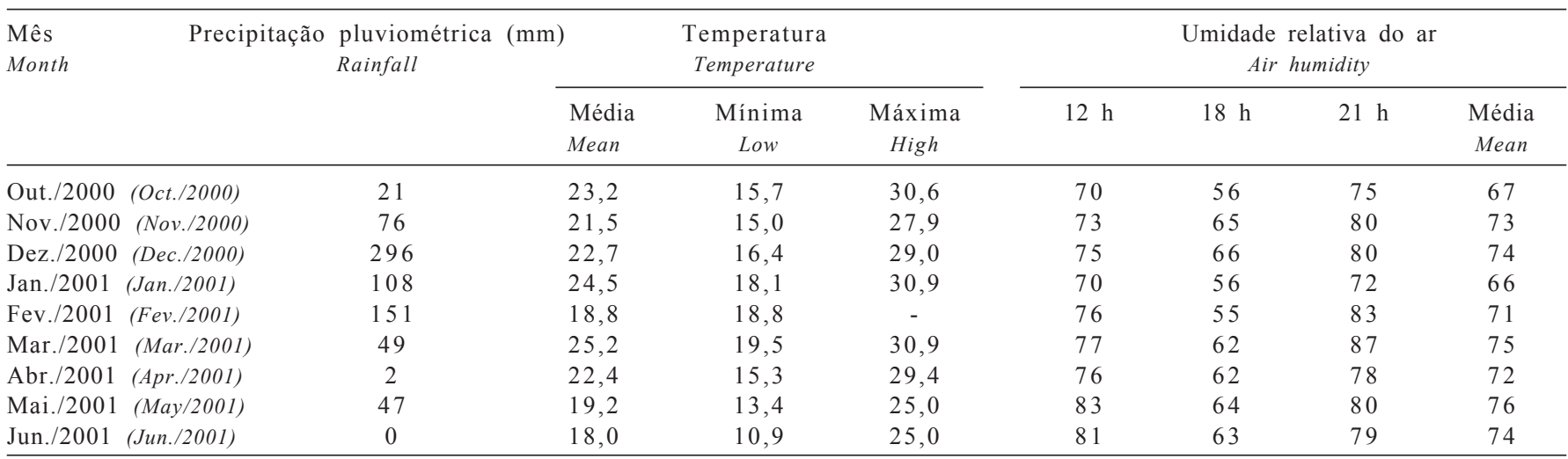


tropical de altitude. Na Tabela 1 são apresentados os dados climáticos durante o período experimental registrados em estação metereológica localizada a $1.000 \mathrm{~m}$ do experimento.

A área do experimento era composta por 66 piquetes de $909 \mathrm{~m}^{2}$, totalizando seis hectares formados com capimelefante cultivar Napier (Pennisetum purpureum Schumacher). Foram avaliados os seguintes tratamentos: pastagem de capim-elefante, sem suplementação com concentrado aos animais $\left(\mathrm{T}_{0}\right)$; pastagem e suplementação com concentrado às vacas até 60 dias pós-parto $\left(\mathrm{T}_{60}\right)$; e pastagem e suplementação com concentrado até 120 dias pósparto $\left(\mathrm{T}_{120}\right)$. O concentrado nos tratamentos $\mathrm{T}_{60}$ e $\mathrm{T}_{120}$ foi fornecido individualmente, na proporção de $1 \mathrm{~kg}$ de concentrado (20\% de PB e $70 \%$ de NDT) para cada $2 \mathrm{~kg}$ de leite produzido acima de $10 \mathrm{~kg} / \mathrm{vaca} / \mathrm{dia}$.

Foram utilizadas 24 vacas Holandês $x$ Zebu de diferentes grupos genéticos, oito por tratamento, distribuídas em blocos ao acaso, com base nos seguintes critérios: produção de leite da lactação anterior, peso vivo, data de parto e grau de sangue. A maioria das parições ocorreu entre outubro e novembro de 2000.

A taxa de lotação foi de 4 vacas/ha e o período de ocupação dos piquetes foi de três dias, com 30 dias de intervalo de desfolha, perfazendo um total de 11 piquetes por tratamento, com duas repetições de área.

A área experimental vem sendo fertilizada anualmente desde 1999 com $1.000 \mathrm{~kg} / \mathrm{h}$ a da fórmula 20:05:20, em três aplicações de um terço cada uma, nos meses de novembro, janeiro e março.

A técnica do pastejo simulado preconizada por Aroeira et al. (1999) foi empregada para seleção de três touceiras de capim-elefante, representando as produções de forragem alta, média e baixa existentes na pastagem antes da entrada dos animais em cada um dos seis piquetes avaliados, observando-se a altura do resíduo pós-pastejo do ciclo anterior. De cada uma dessas touceiras foram removidos manualmente folhas e colmos, simulando pastejo. As amostras foram secas em estufa, para determinação da porcentagem de MS. Após a saída dos animais, o número de touceiras existentes em $49 \mathrm{~m}^{2}$ de cada piquete foi contado. A produção de MS de cada amostra, em cada piquete, em cada época de amostragem, multiplicada pelo número de touceiras por piquete, resultou na estimativa da produção de matéria seca $(\mathrm{kg} / \mathrm{ha})$.

Subamostras de forragem foram retiradas para determinação da composição química (MS, PB, FDN e FDA) e da digestibilidade in vitro da matéria seca (DIVMS), analisadas conforme metodologia descrita por Silva (1998). A análise de nitrogênio foi realizada pelo método de Kjeldahl e o resultado foi multiplicado por 6,25 , para obtenção do teor de PB. As análises de fibra em detergente neutro (FDN) e fibra em detergente ácido (FDA) foram feitas pelo método de Van Soest (1967).

Foram realizadas as análises de variância pelo método de quadrados mínimos, considerando-se o delineamento em blocos completamente ao acaso, por meio do programa SAS (2001), versão 8.1.

\section{Resultados e Discussão}

Os teores médios de MS nas amostras de capim-elefante cv. Napier são descritos na Tabela 2.

Embora nenhuma diferença $(\mathrm{P}<0,05)$ tenha sido observada entre os tratamentos, houve diferença $(\mathrm{P}>0,05)$ entre os meses estudados.

Os teores médios de matéria seca foram de 21,1;22,2 e $21,2 \%$ para os tratamentos $\mathrm{T}_{0}, \mathrm{~T}_{60} \mathrm{e} \mathrm{T}_{120}$, respectivamente. A maior média mensal ocorreu no mês de maio $(26,8 \%)$ e a menor, no mês de dezembro $(17,1 \%)$, provavelmente em razão da dinâmica na população de perfilhos aéreos entre os ciclos de pastejo e/ou da maior ou menor precipitação pluviométrica (Tabela 1). Outro fator que pode explicar os maiores valores em maio e junho é o fato de que, neste período, o capim-elefante inicia a fase de florescimento, acarretando aumento significativo no teor de MS. Os teores de MS obtidos neste trabalho foram aparentemente superiores aos encontrados por Lucci et al. $(1969,1972) \mathrm{e}$ Deresz (1994). Contudo, Erbesdobler et al. (2002) reportou valores semelhantes aos descritos neste trabalho.

Tabela 2 - Médias mensais dos teores de matéria seca (MS) de amostras de capim-elefante cv. Napier, estimadas pela técnica do pastejo simulado, no período de novembro de 2000 a junho de 2001

Table 2 - Monthly averages of dry matter content of samples of elephantgrass cv. Napier estimated by hand plucking technique from November 2000 to June 2001

\begin{tabular}{llccc}
\hline \multirow{2}{*}{$\begin{array}{l}\text { Mês } \\
\text { Month }\end{array}$} & \multicolumn{3}{c}{$\begin{array}{c}\text { Teor de MS (\%) } \\
\text { DM content (\%) }\end{array}$} \\
\cline { 2 - 4 } & $\mathrm{T}_{0}$ & $\mathrm{~T}_{60}$ & $\mathrm{~T}_{120}$ & $\begin{array}{c}\text { Média } \\
\text { Mean }\end{array}$ \\
\hline Nov./2000 (Nov./2000) & 24,4 & 29,2 & 24,9 & $26,2 \mathrm{a}$ \\
Dez./2000 (Dec./2000) & 16,7 & 17,7 & 16,8 & $17,1 \mathrm{e}$ \\
Jan./2001 (Jan./2001) & 21,2 & 19,8 & 21,0 & $20,6 \mathrm{~cd}$ \\
Fev./2001 (Feb./2001) & 18,0 & 20,0 & 19,4 & $19,2 \mathrm{de}$ \\
Mar./2001 (Mar./2001) & 20,4 & 20,5 & 20,5 & $20,4 \mathrm{~cd}$ \\
Mai./2001 (May/2001) & 23,7 & 24,9 & 22,8 & $26,8 \mathrm{~b}$ \\
Jun./2001 (Jun./2001) & 23,5 & 22,9 & 22,9 & $23,1 \mathrm{bc}$ \\
Média (Mean) & $21,1 \mathrm{~A}$ & $22,2 \mathrm{~A}$ & $21,2 \mathrm{~A}$ & \\
CV (\%) & & & & 8,6 \\
\hline
\end{tabular}

Médias seguidas da mesma letra na linha ou na coluna não diferem $(P>0,05)$ pelo teste Student.

Means in a row or column followed by the same letter do not differ $(P>0.05)$ by Student test. 
A quantidade de matéria seca disponível por área ( $\mathrm{t} / \mathrm{ha})$ foi avaliada a cada ciclo e a produção média no período avaliado é apresentada na Tabela 3.

Não houve diferença $(\mathrm{P}<0,05)$ para disponibilidade média de matéria seca entre os tratamentos, entretanto, constataram-se diferenças $(\mathrm{P}<0,01)$ entre as médias mensais, observando-se declínio da disponibilidade de MS à medida que os dias se tornaram mais curtos.

As disponibilidades médias de MS do capim-elefante estimadas antes da entrada dos animais nos piquetes foram de $1.480,1.760$ e $1.870 \mathrm{~kg} / \mathrm{ha}$, respectivamente, para os tratamentos $\mathrm{T}_{0}, \mathrm{~T}_{60}$ e $\mathrm{T}_{120}$. A maior disponibilidade média de forragem foi observada no mês de janeiro de 2001 (2.530 $\mathrm{kg} / \mathrm{ha}$ ) e a menor, no mês de maio de 2001 (440 kg/ha), quando, além de dias mais curtos, foram registradas temperaturas menores e redução severa das precipitações pluviométricas (Tabela 1).

Considerando-se que o período das chuvas se inicia no mês de outubro, atingindo seu ápice entre os meses de dezembro e janeiro e finalizando em meados do mês de maio, pode-se atribuir a este fato a variação da disponibilidade de forragem observada neste estudo.

Não houve efeito $(\mathrm{P}>0,05)$ de tratamentos sobre a disponibilidade de forragem quando se utilizou suplementação

Tabela 3 - Médias mensais da disponibilidade de MS ( $\mathrm{kg} / \mathrm{ha})$ em pastagem de capim-elefante cv. Napier, estimadas pela técnica do pastejo simulado, no período de novembro de 2000 a junho de 2001

Table 3 - Monthly averages of dry matter availability ( $\mathrm{kg} / \mathrm{ha}$ ) of elephantgrass cv. Napier estimated by hand plucking technique, from November 2000 to June 2001

\begin{tabular}{|c|c|c|c|c|}
\hline \multirow[t]{2}{*}{$\begin{array}{l}\text { Mês } \\
\text { Month }\end{array}$} & \multicolumn{4}{|c|}{$\begin{array}{c}\text { Disponibilidade de MS }(\mathrm{kg} / \mathrm{ha}) \\
\text { DM availability }(\mathrm{kg} / \mathrm{ha})\end{array}$} \\
\hline & $\mathrm{T}_{0}$ & $\mathrm{~T}_{60}$ & $\mathrm{~T}_{120}$ & $\begin{array}{l}\text { Média } \\
\text { Mean }\end{array}$ \\
\hline $\begin{array}{l}\text { Nov./2000 } \\
\text { Nov./2000 }\end{array}$ & 1080 & 1380 & 1380 & $1280 \mathrm{~b}$ \\
\hline $\begin{array}{l}\text { Dez./2000 } \\
\text { Dec. } / 2000\end{array}$ & 2090 & 2630 & 2600 & $2440 a$ \\
\hline $\begin{array}{l}\text { Jan. } / 2001 \\
\text { Jan./2001 }\end{array}$ & 2260 & 2460 & 2880 & $2530 a$ \\
\hline $\begin{array}{l}\text { Fev./2001 } \\
\text { Feb./2001 }\end{array}$ & 2020 & 2700 & 2720 & $2480 a$ \\
\hline $\begin{array}{l}\text { Mar./2001 } \\
\text { Mar./2001 }\end{array}$ & 2050 & 2210 & 2200 & $2150 a$ \\
\hline $\begin{array}{l}\text { Mai./2001 } \\
\text { May/2001 }\end{array}$ & 300 & 400 & 610 & $440 \mathrm{c}$ \\
\hline $\begin{array}{l}\text { Jun./2001 } \\
\text { Jun./2001 }\end{array}$ & 580 & 580 & 660 & $610 \mathrm{c}$ \\
\hline $\begin{array}{l}\text { Média } \\
\text { Mean }\end{array}$ & $1480 \mathrm{~A}$ & $1760 \mathrm{~A}$ & $1870 \mathrm{~A}$ & \\
\hline $\begin{array}{l}\text { Total } \\
\text { CV }(\%)\end{array}$ & 10.390 & 12.340 & 13.060 & 18,5 \\
\hline
\end{tabular}

Médias seguidas da mesma letra na linha ou na coluna não diferem $(P>0,05)$ pelo teste Student.

Means in a row or column followed by the same letter do not differ $(P>0.05)$ by Student test. com concentradado, provavelmente em decorrência da pequena quantidade de concentrado fornecido, além do curto período de suplementação, especialmente no tratamento $\mathrm{T}_{60}$.

Há dúvidas, no entanto, se o efeito é substitutivo sobrando mais forragem para os tratamentos com suplementação $\left(\mathrm{T}_{60}\right.$ e $\left.\mathrm{T}_{120}\right)$, o que facilitaria a rebrota, em decorrência da maior quantidade de material fotossinteticamente ativo - ou se o concentrado promove aumento do consumo de forragem, podendo estimular maior perfilhamento, com reflexos sobre a produção de forragem.

A disponibilidade média de forragem neste trabalho pode ser considerada representativa para uma pastagem de capim-elefante adubada com $200 \mathrm{~kg} / \mathrm{ha} /$ ano de $\mathrm{N}$ e de $\mathrm{K}_{2} \mathrm{O}$, visto que produções inferiores foram apresentadas por Erbesdobler etal. (2002) e Andrade \& Gomide (1971). Andrade et al. (2000) e Cóser et al. (1998), por sua vez, reportaram resultados superiores e Cóser et al. (2001), resultados semelhantes aos deste estudo.

Consta na Tabela 4 a quantidade MS disponível/vaca/dia, avaliada a cada ciclo de pastejo, a partir da disponibilidade de matéria seca por área.

Não houve diferença $(\mathrm{P}>0,05)$ na disponibilidade média de MS/vaca/dia entre os tratamentos, porém, as médias mensais apresentaram diferenças $(\mathrm{P}<0,05)$.

Tabela 4 - Médias mensais da disponibilidade de MS (kg/vaca/dia) em pastagem de capim-elefante cv. Napier, estimadas pela técnica do pastejo simulado, no período de novembro de 2000 a junho de 2001

Table 4 - Monthly averages of dry matter availability ( $\mathrm{kg} / \mathrm{cow} / \mathrm{day})$ of elephantgrass CV. Napier estimated by hand plucking technique from November 2000 to June 2001

\begin{tabular}{lcccc}
\hline \multirow{2}{*}{$\begin{array}{l}\text { Mens } \\
\text { Month }\end{array}$} & \multicolumn{4}{c}{$\begin{array}{c}\text { Disponibilidade de MS (kg/vaca/dia) } \\
\text { DM availability }\end{array}$} \\
\cline { 2 - 5 } & $\mathrm{T}_{0}$ & $\mathrm{~T}_{60} /$ cow/day) & $\mathrm{T}_{120}$ & $\begin{array}{c}\text { Média } \\
\text { Mean }\end{array}$ \\
\hline $\begin{array}{l}\text { Nov./2000 } \\
\text { Nov./2000 } \\
\text { Dez./2000 } \\
\text { Dec./2000 }\end{array}$ & 9,02 & 11,50 & 11,51 & $10,7 \mathrm{~b}$ \\
Jan./2001 & 17,44 & 21,92 & 21,69 & $20,3 \mathrm{a}$ \\
Jan./2001 & 18,81 & 20,46 & 24,03 & $21,1 \mathrm{a}$ \\
$\begin{array}{l}\text { Fev./2001 } \\
\text { Feb./2001 }\end{array}$ & 16,83 & 22,49 & 22,65 & $20,7 \mathrm{a}$ \\
$\begin{array}{l}\text { Mar./2001 } \\
\text { Mar./2001 }\end{array}$ & 17,11 & 18,38 & 18,36 & $18,0 \mathrm{a}$ \\
$\begin{array}{l}\text { Mai./2001 } \\
\text { May/2001 }\end{array}$ & 2,53 & 3,31 & 5,08 & $3,6 \mathrm{c}$ \\
Jun./2001 & 4,84 & 4,81 & 5,51 & $5,1 \mathrm{c}$ \\
$\begin{array}{l}\text { Jun./2001 } \\
\text { Média }\end{array}$ & $12,37 \mathrm{~A}$ & $14,70 \mathrm{~A}$ & $15,55 \mathrm{~A}$ & \\
$\begin{array}{l}\text { Mean } \\
\text { CV (\%) }\end{array}$ & & & & 18,5 \\
\hline
\end{tabular}

Médias seguidas da mesma letra na linha ou na coluna não diferem $(P>0,05)$ pelo teste Student.

Means in a row or column followed by the same letter do not differ $(P>0.05)$ by Student test. 
A disponibilidade de MS por vaca por dia variou conforme a disponibilidade por área, de modo que os valores absolutos de disponibilidade foram semelhantes entre os tratamentos $\mathrm{T}_{60}$ e $\mathrm{T}_{120}$ até os primeiros 60 dias de experimento, quando o tratamento $\mathrm{T}_{120}$ apresentou maior disponibilidade. As disponibilidades de MS/vaca/dia foram de 12,$4 ; 14,7$ e $15,6 \mathrm{~kg} / \mathrm{vaca} /$ dia para os tratamentos $\mathrm{T}_{0}, \mathrm{~T}_{60}$, $\mathrm{T}_{120}$, respectivamente. A maior média foi obtida no mês de fevereiro $(20,7 \mathrm{~kg} / \mathrm{vaca} / \mathrm{dia})$ e a menor, no mês de maio (3,6 kg/vaca/dia).

Não houve diferença $(\mathrm{P}>0,05)$ entre os tratamentos quanto à disponibilidade média de MS/vaca/dia. Durante os meses de dezembro de 2000, janeiro, fevereiro e março de 2001, os valores médios de disponibilidade de MS/ vaca/dia não limitaram o consumo de MS dos animais em nenhum dos tratamentos. Resultados inferiores foram encontrados por Deresz (2001).

A produção média de leite foi de 11,65 kg/vaca/dia. A ausência de resposta $(\mathrm{P}<0,05)$ na produção de leite entre os tratamentos nas estratégias de suplementação com concentrado pode ser atribuída à oferta suficiente de nutrientes provenientes da forragem ou ao fato de os animais utilizados não apresentarem potencial genético para atingir produções de leite mais elevadas (Tabelas 5 e 6). Deresz (2001) concluiu que vacas mestiças Holandês x Zebu com potencial de produção de leite de até $15 \mathrm{~kg} /$ dia no início da lactação, podem ser manejadas em pastagem de capim-elefante com taxa de lotação de 4,5 vacas/ha, sem suplementação concentrada durante o período das chuvas.

Nas análises bromatológicas da forragem estudada, não foram encontradas diferenças $(\mathrm{P}>0,05)$ entre os tratamentos para os teores de PB, FDN, FDA e DIVMS, porém houve diferenças $(\mathrm{P}<0,05)$ entre todas as variáveis nas médias dos meses observados (Tabela 7).

Tabela 5 - Produção média de leite (kg/vaca/dia) corrigida para $4 \%$ de gordura de vacas Holandês $x$ Zebu manejadas em pastagem de capim-elefante utilizando-se suplementação com concentrado

Table 5 - Means of milk yield ( $\mathrm{kg} /$ cow/day) corrected for $4 \%$ of milk fat of Holstein $x$ Zebu cows grazing elephantgrass, using strategies of concentred supplementation

\begin{tabular}{lc}
\hline $\begin{array}{l}\text { Tratamento } \\
\text { Treatment }\end{array}$ & $\begin{array}{c}\text { Produção de leite } \\
\text { Milk yield }\end{array}$ \\
\hline $\mathrm{T}_{0}$ & $11,0 \mathrm{a}$ \\
$\mathrm{T}_{60}$ & $11,6 \mathrm{a}$ \\
$\mathrm{T}_{120}$ & $12,3 \mathrm{a}$ \\
Média & 11,7 \\
Mean & 21,3 \\
CV (\%) & 21,7 \\
\hline
\end{tabular}

Médias seguidas da mesma letra na coluna não diferem $(P>0,05)$ pelo teste Student.

Means in a column followed by the same letter do not differ $(P>0.05)$ by Student test.
O maior teor de PB foi de 17,11\% e o menor, de 10,81\%, nos meses de abril de 2001 e novembro de 2000 , respectivamente. Este fato pode ser atribuído à dinâmica de perfilhamento, registrando-se ciclos com maior número de perfilhos com menor idade e, conseqüentemente, com maior teor de PB.

O teor médio de $\mathrm{PB}$ encontrado durante o experimento foi de $13,58 \%$, abaixo dos valores esperados para o capimelefante adubado com $200 \mathrm{~kg} / \mathrm{ha}$ de $\mathrm{N}$ e manejado com 30 dias de descanso. Os teores de PB determinados neste experimento para o capim-elefante estão acima do valor limitante ao consumo voluntário, que é de 7\%, segundo Milford \& Minson (1966).

Valores semelhantes foram relatados por Deresz (2001) e Gomide et al. (1969), enquanto Deresz (1994) e Gomide et al. (1969) observaram valores superiores e Aroeira et al. (1999), valores inferiores aos deste trabalho.

O teor médio de FDN encontrado neste trabalho foi de $69,14 \%$, variando entre $74,08 \%$ (fevereiro) e $62,33 \%$ (abril).

Não se observou a relação entre os teores de PB e FDN esperada nos meses experimentais. Esta relação ocorreu apenas no mês de abril, quando o maior teor de PB correspondeu ao menor de FDN.

Erbesdobler et al. (2002), Deresz (1994) e Soares et al. (1998) encontraram valores inferiores, enquanto Soares et al.(1998) e Aroeira et al. (1999), valores semelhantes ao deste trabalho.

O teor médio de FDA foi de 39,47\%, variando de 37,34 a $41,99 \%$ nos meses de dezembro e fevereiro, respectivamente.

Valores semelhantes foram obtidos por Deresz (1994) e Soares et al. (1998). Teores superiores foram descritos por Deresz (1994) e Aroeira et al. (1999), ao passo que Soares et al. (1998) e Silveira et al. (1973) relataram valores abaixo dos obtidos neste trabalho.

Tabela 6 - Produção média de leite (kg/vaca/dia) corrigida para $4 \%$ de gordura de vacas Holandês $x$ Zebu manejadas em pastagem de capim-elefante utilizando-se suplementação com concentrado

Table 6 - Means milk yield ( $\mathrm{kg} / \mathrm{cow} /$ day) corrected for $4 \%$ of milk fat of cows Holstein x Zebu grazing elephantgrass using strategies of concentrate supplementation

\begin{tabular}{lc}
\hline $\begin{array}{l}\text { Estádio de lactação } \\
\text { Lactation stage }\end{array}$ & $\begin{array}{c}\text { Produção de leite } \\
\text { Milk yield }\end{array}$ \\
\hline Até 60 dias (Up to 60 days) & $15,1 \mathrm{a}$ \\
60 a 120 dias (60 to 120 days) & $11,6 \mathrm{~b}$ \\
$>120$ dias (After 120 days) & $8,2 \mathrm{c}$ \\
Média & 11,6 \\
Mean & \\
CV $(\%)$ & 21,3 \\
\hline
\end{tabular}

Médias seguidas da mesma letra na coluna não diferem $(P>0,05)$ pelo teste Student.

Means in a column followed by the same letter do not differ $(P>0.05)$ by Student test. 
Tabela 7 - Médias mensais dos teores de PB, FDN, FDA e DIVMS para o capim-elefante, estimadas pela técnica do pastejo simulado, no período de novembro de 2000 e junho de 2001

Table 7 - Monthly averages of CP, NDF, ADF, and IVDMD of elephantgrass pasture cv. Napier estimated by hand plucking technique from November, 2000 to June, 2001

\begin{tabular}{|c|c|c|c|c|c|}
\hline \multirow[t]{2}{*}{$\begin{array}{l}\text { Mês } \\
\text { Month }\end{array}$} & \multirow[b]{2}{*}{$\begin{array}{l}\text { Tratamento } \\
\text { Treatment }\end{array}$} & \multicolumn{4}{|c|}{$\begin{array}{c}\text { Teor na MS (\%) } \\
\text { DM content (\%) }\end{array}$} \\
\hline & & $\begin{array}{l}\mathrm{PB} \\
C P\end{array}$ & $\begin{array}{l}\mathrm{FDN} \\
N D F\end{array}$ & $\begin{array}{l}\text { FDA } \\
A D F\end{array}$ & $\begin{array}{l}\text { DIVMS } \\
I V D M D\end{array}$ \\
\hline $\begin{array}{l}\text { Nov./2000 } \\
\text { Nov./2000 }\end{array}$ & $\begin{array}{l}\text { T } 0 \\
\text { T } 60 \\
\text { T } 120 \\
\text { Média } \\
\text { Mean }\end{array}$ & $\begin{array}{l}10,81 \\
11,55 \\
11,33 \\
11,23 \mathrm{c}\end{array}$ & $\begin{array}{l}73,42 \\
72,64 \\
72,79 \\
72,95 \mathrm{a}\end{array}$ & $\begin{array}{l}38,93 \\
38,12 \\
38,25 \\
38,63 \mathrm{a}\end{array}$ & $\begin{array}{l}64,65 \\
65,17 \\
64,50 \\
64,78 \mathrm{~b}\end{array}$ \\
\hline $\begin{array}{l}\text { Dez./2000 } \\
\text { Dec./2000 }\end{array}$ & $\begin{array}{l}\text { T } 0 \\
\text { T } 60 \\
\text { T } 120 \\
\text { Média } \\
\text { Mean }\end{array}$ & $\begin{array}{l}14,07 \\
13,54 \\
13,64 \\
13,75 b\end{array}$ & $\begin{array}{l}62,69 \\
61,94 \\
63,98 \\
62,96 \mathrm{c}\end{array}$ & $\begin{array}{l}35,50 \\
36,34 \\
40,18 \\
37,34 \mathrm{a}\end{array}$ & $\begin{array}{l}68,07 \\
69,25 \\
68,88 \\
68,74 \mathrm{a}\end{array}$ \\
\hline $\begin{array}{l}\text { Jan./2001 } \\
\text { Jan./2001 }\end{array}$ & $\begin{array}{l}\text { T } 0 \\
\text { T } 60 \\
\text { T } 120 \\
\text { Média } \\
\text { Mean }\end{array}$ & $\begin{array}{l}12,98 \\
13,39 \\
12,07 \\
12,81 b\end{array}$ & $\begin{array}{l}67,73 \\
69,94 \\
68,56 \\
68,75 b\end{array}$ & $\begin{array}{l}40,30 \\
42,54 \\
41,27 \\
41,37 \mathrm{a}\end{array}$ & $\begin{array}{l}- \\
- \\
- \\
-\end{array}$ \\
\hline $\begin{array}{l}\text { Fev./2001 } \\
\text { Feb./2001 }\end{array}$ & $\begin{array}{l}\text { T } 0 \\
\text { T } 60 \\
\text { T } 120 \\
\text { Média } \\
\text { Mean }\end{array}$ & $\begin{array}{l}13,87 \\
14,59 \\
14,21 \\
14,23 b\end{array}$ & $\begin{array}{l}72,13 \\
74,60 \\
75,49 \\
74,08 \mathrm{a}\end{array}$ & $\begin{array}{l}42,98 \\
42,65 \\
40,35 \\
41,99 a\end{array}$ & $\begin{array}{l}58,54 \\
56,82 \\
61,81 \\
59,06 \mathrm{a}\end{array}$ \\
\hline $\begin{array}{l}\text { Mar./2001 } \\
\text { Mar./2001 }\end{array}$ & $\begin{array}{l}\text { T } 0 \\
\text { T } 60 \\
\text { T } 120 \\
\text { Média } \\
\text { Mean }\end{array}$ & $\begin{array}{l}14,52 \\
12,69 \\
13,74 \\
13,65 b\end{array}$ & $\begin{array}{l}70,04 \\
76,61 \\
74,59 \\
73,75 a\end{array}$ & $\begin{array}{l}35,57 \\
38,35 \\
40,02 \\
37,98 \mathrm{a}\end{array}$ & $\begin{array}{l}- \\
- \\
- \\
-\end{array}$ \\
\hline $\begin{array}{l}\text { Abr./2001 } \\
\text { Apr./2001 }\end{array}$ & $\begin{array}{l}\text { T0 } \\
\text { T } 60 \\
\text { T } 120 \\
\text { Média } \\
\text { Mean }\end{array}$ & $\begin{array}{l}15,08 \\
17,11 \\
15,29 \\
15,83 \mathrm{a}\end{array}$ & $\begin{array}{l}63,99 \\
63,07 \\
59,94 \\
62,33 \mathrm{c}\end{array}$ & $\begin{array}{l}- \\
- \\
- \\
-\end{array}$ & $\begin{array}{l}63,90 \\
63,19 \\
60,44 \\
62,51 \mathrm{ab}\end{array}$ \\
\hline $\begin{array}{l}\text { Média } \\
\text { Mean }\end{array}$ & & 13,58 & 69,14 & 39,47 & 63,77 \\
\hline CV (\%) & & 5,32 & 2,76 & 4,68 & 2,88 \\
\hline
\end{tabular}

Médias seguidas da mesma letra na coluna não diferem $(P>0,05)$ pelo teste Student.

Means in a column followed by the same letter do not differ $(P>0.05)$ by Student test.

O valor médio de DIVMS foi de $63,77 \%$, variando entre $59,06 \%$ (mês de fevereiro) e 68,74\% (mês de dezembro).

Em virtude de problemas ocorridos nas análises bromatológicas, não foram relatados os teores médios de DIVMS nos meses de janeiro e março, o que impede a avaliação desta variável na gramínea estudada.

Hillesheim (1987) e Cóser et al. (2001) encontraram valores semelhantes aos descritos neste trabalho, ao passo que Deresz (1994) e Cóser et al. (1999) reportaram valores mais elevados.

\section{Conclusões}

O capim-elefante cv. Napier apresentou variação na composição química, na digestibilidade e na disponibilidade de forragem durante os meses de pastejo.

A disponibilidade de matéria seca por área $(\mathrm{kg} / \mathrm{ha})$, a composição química e a digestibilidade da forragem de capim-elefante cv. Napier durante o período das chuvas foram suficientes para atender às necessidades de mantença e produção média de $12 \mathrm{~kg} / \mathrm{vaca} /$ dia de leite durante a lactação.

\section{Literatura Citada}

AIKEN, G.E.; BRANSBY, D.I. Observer variability for disk meter measurements of forage mass. Agronomy Journal, v.84, n.4, p.603-605, 1992 .

ANDRADE, A.C.; FONSECA, D.M.; GOMIDE, V.H.A. et al. Produtividade e valor nutritivo da capim-elefante cv. Napier sob doses crescentes de nitrogênio e potássio. Revista Brasileira de Zootecnia, v.19, n.6, p.1589-1593, 2000.

ANDRADE, L.F.; GOMIDE, J.A. Curvas de crescimento e valor nutritivo do capim-elefante (Pennisetum purpureum Schim.) Revista Ceres, v.100, p.431-447, 1971.

AROEIRA, L.J.M.; LOPES, F.C.F.; DERESZ, F. et al. Pasture availability and dry matter intake of lactating crossbred cows grazing elephantgrass (Pennisetum purpureum, Schum.). Animal Feed Science and Technology, v.78, p.313-324, 1999.

AROEIRA, L.J.M.; MARTINS, C.E.; CÓSER, A.C. et al. Sistemas alternativos para produção de leite e carne a pasto. In: MARTINS, C.E.; CÓSER, A.C.; ALENCAR, C.A.B. (Eds.) Sustentabilidade da pecuária de leite e de corte da Região do Leste Mineiro. Juiz de Fora: Embrapa Gado de Leite, 2004. p.31-50.

CÓSER, A.C.; DERESZ, F.; MARTINS, C.E. Período de utilização de Capim-elefante em pastagens. Informe Agropecuário, v.198, n.192, p.33-35, 1998.

CÓSER, A.C.; MARTINS, C.E.; CARDOSO, F. P. N. Produção de leite em pastagem de capim-elefante submetida a duas alturas de resíduo pós-pastejo. Ciência e Agrotecnologia, v.75, n.2, p. 417-423, 2001.

CÓSER, A.C.; MARTINS, C.E.; FONSECA, D.M. et al. Efeito de diferentes períodos de ocupação da pastagem de capim-elefante sobre a produção de leite. Pesquisa Agropecuária Brasileira v.34, n.5, p.861-866, 1999.

COSTA, M.G.; CAMPOS, J.M.S.; VALADARES FILHO, S.C. et al Desempenho produtivo de vacas leiteiras alimentadas com diferentes proporções de cana-de-açúcar e concentrado ou silagem na dieta. Revista Brasileira de Zootecnia, v.34, n.6, p.2437-2445, 2005 (supl.).

DERESZ, F. Produção de leite de vacas mestiças Holandês x Zebu em pastagem de capim-elefante, manejada em sistema com e sem suplementação durante a época das chuvas. Revista Brasileira de Zootecnia, v.30, n.1, p.197-204, 2001.

DERESZ, F. Manejo de pastagem de capim-elefante. In: SIMPÓSIO SOBRE CAPIM-ELEFANTE, 2., 1994, Juiz de Fora. Anais... Coronel Pacheco: EMBRAPA-CNPGL, 1994. p.116-137.

ERBESDOBLER, E.D.; FONTES, C.A.A.; QUEIROZ, D.S. et al. Avaliação do consumo e ganho de peso de novilhos em pastejo rotacionado de capim-elefante (Pennisetum purpureum, Schum.), cv. Napier, na estação chuvosa. Revista Brasileira de Zootecnia, v.31, n.5, p.2123-2128, 2002.

ESTRADA, C.L.H.; NASCIMENTO JR., D.; REGAZZI, A.J. Efeito do número e tamanho do quadrado nas estimativas pelo Botanal da composição botânica e disponibilidade de matéria seca de 
pastagens cultivadas. Revista da Sociedade Brasileira de Zootecnia, v.20, n.5, p.483-493, 1991.

GOMIDE, J.A.; NOLLER, C.H.; MOTT, G.O. et al. Effect of plant age and nitrogen fertilization on chemical composition and in vitro cellulose digestibility in tropical grasses. Agronomy Journal, v.61, p.120-123, 1969.

HILLESHEIM, A. Fatores que afetam o consumo e perdas de capim-elefante (Pennisetum purpureum, Schum.) sob pastejo. Piracicaba: Escola Superior de Agricultura Luiz de Queiroz, 1987. 94p. Dissertação (Mestrado em Agronomia) Escola Superior de Agricultura Luiz de Queiroz, 1987.

LUCCI, C.S.; ROCHA, G.L.; FREITAS, E.A.N. Produção de leite em regime exclusivo de pastagem de capins fino e Napier. Boletim de Indústria Animal, v.29, n.1, p.45-51, 1972.

LUCCI, C.S.; ROCHA, G.L.; KALIL, E.B. Produção de leite em pastos de capim fino (Brachiaria mutica) e de capim napier (Pennisetum purpureum) Boletim da Industria Animal, v.26, n. único, p.275-284, 1969.

MILFORD, R. E.; MINSON, D. J. Intake of tropical pastures species. In: CONGRESSO INTERNACIONAL DE PASTAGENS, 9., São Paulo, 1966. Anais... São Paulo: 1966. p.815-822.

O'ROURKE, P.K.; McCOSKER, T.H.; TEITZEL, J.K. et al. Application and appraisal of a visual estimation technique for composition and yield sampling of grasslegume pastures in the wet tropics of north-eastern Australia. Australian Journal Experimental Agriculture Animal Husbandry, v.24, n.127, p.535-542, 1984.
STATISTICAL ANALYSIS SYSTEM - SAS. User's guide. Cary: 2001.

SILVA, D.J. Análise de alimentos: métodos químicos e biológicos. 2.ed. Viçosa, MG: Universidade Federal de Viçosa, 1998. 166p.

SILVEIRA, A.J.; SANTANA, D.P.; PEREIRA, M.P. Efeito do tamanho do saco plástico e do método de semeadura no desenvolvimento de mudas de café. Seiva, v.33, n.77, p.14-18, 1973.

SOARES, J.P.G.; AROEIRA, L. J. M.; PEREIRA, O. G. et al. Capimelefante (Pennisetum purpureum Schum.) sob duas doses de nitrogênio. Consumo e produção de leite. Revista Brasileira de Zootecnia, v.28, n.4, p.889-897, 1998.

Van SOEST, P.J. Development of a comprehensive system for analysis and its application to forage. Journal of Animal Science, v.26, n.1, p.119-128, 1967. 